\title{
The role of two parasitological staining techniques in diagnosis of cryptosporidiosis among diarrhoeic patient's admitted to kosti teaching hospital, white nile state, sudan
}

\begin{abstract}
Background: Cryptosporidiosis is the disease caused by Cryptosporidium parvum, which associated with economic losses and the public health problems in human.

Objectives: The aim of this study was to detect C.parvum, compare between modified ZN staining technique and trichrome staining and study the role of a parasitological techniques for recovery of cryptosporidiosis among diarrheic patient's admitted to Kosti teaching hospital, White Nile State, Kosti city, Sudan. This representative is a comparative study was conducted from August 2016 to April 2017.

Methods: A total of three hundred stool samples were collected from diarrheic patients, the samples were examined using Formal ether concentration technique and staining techniques and the samples were preserved in schauddins fixative.

Results: The overall results of parasite detected by modified ZN stain was $18 \%$, and by trichrome stain $5 \%$. The detection of C.parvum was higher in female than male.

Conclusion: The study showed that modified $\mathrm{ZN}$ staining technique is the most sensitive and accurate so will be recommended to be use as first choice in diagnosis of Cryptosporiduim parvum.
\end{abstract}

Keywords: Cryptosporidiosis, modified ZN staining technique, Trichrome staining technique, parasitological techniques
Volume 7 Issue 2 - 2018

\author{
Abdelhakam G Tamomh, 1,2 Mohammed \\ A Suliman, ${ }^{2}$ Kabulo K Cedric, ${ }^{3} \mathrm{Hafiz} Y$ \\ Mohammed, ${ }^{2}$ Abdalmoneim M Magboul, ${ }^{2}$ \\ Ibrahim M Hassan, ${ }^{2}$ Rabah M Ibrahim, ${ }^{2}$ \\ Ammar A Abdalla, ${ }^{2}$ Tarteel A Abdallah, ${ }^{2}$ \\ Ahmed A Alfaki ${ }^{2}$ \\ 'College of Medical laboratory sciences, Dalian Medica \\ University, China \\ ${ }^{2}$ Department of Parasitology and Medical Entomology, \\ University of El Imam El Mahdi, Sudan. \\ ${ }^{3}$ Department of Stomatology, Dalian Medical University, China \\ Correspondence: Abdelhakam G Tamomh, I- College of \\ Medical laboratory sciences, Dalian Medical University, Dalian, \\ China, 2- Department of Parasitology and Medical Entomology, \\ Faculty of Medical Laboratory Sciences, University of El Imam El \\ Mahdi, Kosti, Sudan, Tel +86I884I I 5334I, +2499I5025448, \\ Email abdelhakam738@mahdi.edu.sd, abdelhakam738@gmail. \\ com
}

Received: February 0I, 20I8 | Published: March 08, 2018

\section{Introduction}

Cryptosporidiosis is parasitic diseases of the intestinal tract which causes diarrhea in developing countries. Primary symptoms are acute, watery, and no bloody diarrhea and infection is of particular concern in immunocompromised patients. ${ }^{1}$ Molecular techniques have shown that Cryptosporidium parvum is the predominant species in cryptosporidiosis, accounting $50.8 \%$ of cases among 325 water-borne parasitic diseases worldwide. In stool examination of patients with gastroenteritis, the reported frequency of Cryptosporidium was 1-4\% in Europe and North America; and 3-20\% in Africa, Asia, Australia, South and Central America. ${ }^{1}$ Peaks in the prevalence, in developed countries was observed in the late summer season., ${ }^{2,3}$ In developing countries, the infection is common in infants less than 1 year, but was rarely seen in adults. Asymptomatic carriage, as determined by stool surveys, generally occurs at very low rates in industrialized countries, although in day care centers higher rates had been reported. ${ }^{4-6}$ The high rates of asymptomatic carriage $10-30 \%$ were common in nonindustrialized countries. ${ }^{1}$ Seroprevalence rates are generally higher than fecal carriage rates, from $25-35 \%$ in industrialized countries up to $68-88 \%$ in Russia and $95 \%$ in South America. ${ }^{7,8}$
Seroprevalence rates increase with increasing age and are relatively high in dairy farmers and day care centre attendants. ${ }^{9-11}$ Studies conducted in USA showed that people consuming treated surface water were more likely to show sero conversion during the study period than the people who consumed well-protected groundwater, during the months of the study. A significant proportion of the population exhibited seroconversion also in the groundwater cities, indicating that Cryptosporidium infections may be relatively common. Illness rates were not increased in the cities supplied with surface water, although infections were more common. ${ }^{12,13}$ In this study we explain the role of a parasitological techniques in recovery of cryptosporidiosis among diarrheic patient's admitted to Kosti teaching hospital, White Nile State, Kosti city, Sudan. Our study recommended the uses of permanent staining techniques as routine parasitological examination in developing countries which help in misdiagnose and early discovery of the disease might help to control and prevention.

\section{Materials and methods}

\section{Study area}

Study was conducted in Kosti city, White Nile State, Sudan ${ }^{14}$ 


\section{Study design}

The design of this study is a hospital based a quantitivecomparative study

\section{Study population, inclusion and exclusion criteria}

The study included patients selected randomly from both sexes with different ages groups (from 1 year to over 50 yrs old) complained with diarrhoea who admitted to Kosti Teaching Hospital between August 2016 and April 2017. The participants will be enrolled after qualifying the selection criteria; approved informed consent according to number (1-300 patient), age (from 1-25yrs, 26-50yrs and over $50 y r s$ age groups)), sex (both male and female), water supply ( from pipe, canal and donkey cart water sources), latrine in houses (present or absent), patients had diarrhoea and abdominal symptoms included. Patients with bacillary dysentery or treated with antidiarrhial drugs or antiparasitic drug before the time of collection excluded.

\section{Data collection and analysis}

Specimens collected randomly and information's were collected. Questionnaire covering all information was contracted. The patient data recorded, sample collected, logistic and patient safety issue handled according to the protocols seted out by the health facilities. The raw data stored using two systems: Firstly, the questionnaire papers securely stored at a specific place to be used as back-up. Secondly, the data is saved in two electronic packages (Excel and SPSS programmes) for analysis. Within the databases, cases are identified by number only. Data will be recorded and then analysed using Chisquare test for frequency and distribution used by statistical package of social science (SPSS version 16) program. P values $<0.05$ will be considered significant for all statistical analysis.

\section{Sample collection and ethics}

Three hundred samples were collected from Kosti Teaching Hospital attending to agreement of hospital manager and staff of the hospital laboratory. The Schaudinns fixative, the trichrome stain and modified Ziehl Neelsen stain prepared as described by Tamomh et al. ${ }^{15}$

\section{Stool sample collection and processing}

In clean and dry stool container, collect small amount of diahrriac patient stool. Firstly used direct stool examination, and then used concentration technique; followed by smear prepared from fresh sample, fixed by covering the smears by methanol about 3 minute and later stained by ziehl neelsen stain. The remaining amount of sample preserved by schauddin fixitive, and later used.

\section{Discussion}

Three hundred stool samples were collected, screened for Cryptosporidium parvum using modified Ziehl Neelsen staining technique and trichrome staining technique. The overall frequency of Cryptosporidiosis was detected by modified Ziehl Neelsen staining technique $54(18 \%)$ in Table 1 this result is in agreement with the results obtained by, ${ }^{1}$ whom found the prevalence of cryptosporidiosis were $(3-20 \%)$. The high recovery of parasite was detected in age group $26-50$ years $25(46.4 \%)$ using modified Ziehl Neelsen stain in Table 2 and clearly in (Figure 1), this result was agreement with ${ }^{9,11,7}$ whom found that the infection increase with the same age group and disagree with; ${ }^{16}$ whom found that $31.5 \%$ of all children less than 2 years of age are infected. The high prevalence was detected in female $30(55.5 \%)$ more than male $24(44.5 \%)$ by modified Zeihl Nelson staining technique in Table 3, this due to female directly contact with children infected with cryptosporidiosis and working in farms. this result were disagreement with Park et al., ${ }^{6}$ which is found the high infection in male $(1.9 \%)$ more than female $(1.2 \%)$.

Table I The number and percentage of infected and non infected cases with cryptosporidium parvum using the Trichrome staining technique and Modified Ziehl Neelsen staining technique

\begin{tabular}{llll}
\hline \multicolumn{1}{c}{ Techniques } & $\begin{array}{l}\text { Trichrome } \\
\text { staining } \\
\text { technique }\end{array}$ & $\begin{array}{l}\text { Modified } \\
\text { Ziehl Neelsen } \\
\text { staining } \\
\text { technique }\end{array}$ & P value \\
\hline Infected cases & $15(5 \%)$ & $54(18 \%)$ & \\
Non infected cases & $285(95 \%)$ & $246(82 \%)$ & 0.000 \\
Total & $300(100 \%)$ & $300(100 \%)$ &
\end{tabular}

Table 2 The number and percentage of infected cases with cryptosporidium parvum using the Ziehl Neelsen staining technique and Trichrome staining techniques correlated with age group

\begin{tabular}{llll}
\multicolumn{1}{c}{ Techniques } & $\begin{array}{l}\text { Modified Ziehl } \\
\text { Neelsen staining } \\
\text { technique }\end{array}$ & $\begin{array}{l}\text { Trichrome } \\
\text { staining } \\
\text { technique }\end{array}$ & P value \\
I-25yrs & II (20.3\%) & $2(13.4 \%)$ & \\
$26-50$ & $25(46.4 \%)$ & $9(60 \%)$ & 0.046 \\
Over 50yrs & $18(33.3 \%)$ & $4(26.6 \%)$ & \\
Total & $54(100 \%)$ & $15(100 \%)$ &
\end{tabular}

Figure I Frequency distribution and detection of $C$. parvum in different demographic factors using the two staining techniques

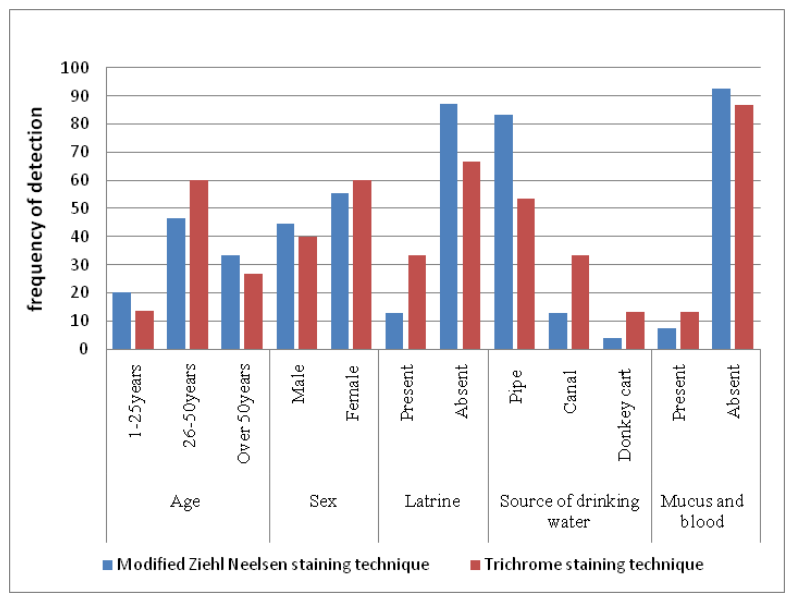

The greater number of parasite was detected in patients who haven't latrine in there, Table 4. This may be due to personal hygiene and defecation in the open and contamination of food or water which aid in the transmission of disease. High prevalence is found in people whom consumed pipe water $45(83.4 \%)$ in Table 5 this may due to water purification station not clearing periodically and not sanitation by optimum method, this result agreement with ${ }^{12}$ whom found in pipe water consumed people because consumed treated surface water were more likely to infected than the people that consumed well protected ground water (Table 6). ${ }^{17-20}$ 
Table 3 The number and percentage of infected cases with cryptosporidium parvum in relation to sex using the Modified Ziehl Neelsen staining technique and Trichrome staining techniques

\begin{tabular}{llll}
\hline Techniques & $\begin{array}{l}\text { Modified Ziehl } \\
\text { Neelsen staining } \\
\text { technique }\end{array}$ & $\begin{array}{l}\text { Trichrome } \\
\text { staining } \\
\text { technique }\end{array}$ & P value \\
Male & $24(44.5 \%)$ & $6(40 \%)$ & \\
Female & $30(55.5 \%)$ & $9(60 \%)$ & 0.028 \\
Total & $54(100 \%)$ & $15(100 \%)$ &
\end{tabular}

Table 4 The number and percentage of infected cases with cryptosporidium parvum according to the latrine facility using the Modified Ziehl Neelsen staining technique and Trichrome staining techniques

\begin{tabular}{llll} 
Techniques & $\begin{array}{l}\text { Modified Ziehl } \\
\text { Neelsen staining } \\
\text { technique }\end{array}$ & $\begin{array}{l}\text { Trichrome } \\
\text { staining } \\
\text { technique }\end{array}$ & P value \\
\hline $\begin{array}{l}\text { Cases } \\
\text { Present }\end{array}$ & $\begin{array}{l}(12.97 \%) \\
\text { Absent }\end{array}$ & $5(33.3 \%)$ & \\
Total & $54(100 \%)$ & $10(66.7 \%)$ & 0.066 \\
\hline
\end{tabular}

Table 5 The number and percentage of infected cases with cryptosporidium parvum in according to sources of drinking water using the Modified Ziehl Neelsen staining technique and Trichrome staining techniques

\begin{tabular}{|c|c|c|c|}
\hline Cases & $\begin{array}{l}\text { Modified Ziehl } \\
\text { Neelsen staining } \\
\text { technique }\end{array}$ & $\begin{array}{l}\text { Trichrome } \\
\text { staining } \\
\text { technique }\end{array}$ & $P$ value \\
\hline Pipe & 45 (83.4\%) & $8(53.4 \%)$ & \\
\hline Canal & 7 (I2.9\%) & $5(33.3 \%)$ & 0.048 \\
\hline Donkey cart & $2(3.7 \%)$ & 2 (I3.3\%) & \\
\hline Total & 54 (I00\%) & 15 (I00\%) & \\
\hline \multicolumn{4}{|c|}{$\begin{array}{l}\text { Table } 6 \text { The number and percentage of infected cases with a cryptosporidium } \\
\text { parvum according to the mucus and blood using the Modified Ziehl Neelsen } \\
\text { staining technique and Trichrome staining techniques }\end{array}$} \\
\hline Cases & $\begin{array}{l}\text { Modified Ziehl } \\
\text { Neelsen staining } \\
\text { technique }\end{array}$ & $\begin{array}{l}\text { Trichrome } \\
\text { staining } \\
\text { technique }\end{array}$ & $P$ value \\
\hline Present & $4(7.4 \%)$ & $2(13.3 \%)$ & \\
\hline Absent & $50(92.6 \%)$ & $13(86.7 \%)$ & 0.471 \\
\hline Total & $54(100 \%)$ & $15(100 \%)$ & \\
\hline
\end{tabular}

\section{Limitations and strength of the study}

The recruitment participants across various data and the staining used as routine parasitological techniques had strengthened the external validity and generalizability of the study findings which might improve the public health in developing countries. Since the questionnaire were not pretested/validated as it was self developed general questionnaire. The questions of the survey were not used by any other study and they were not tested for their reliability.

\section{Conclusion}

Our results suggest Cryptosporidium is an important protozoan parasite that causes enteric infection in human and important to develop a routine examination of the parasites in developing countries to improve the public health. The routine parasitological examinations in developing countries might be including permanent staining techniques such as modified $\mathrm{ZN}$ staining technique to detect the parasitic disease early and improve the health status of diarrheic patients. Also the most sensitive and accurate technique is modified $\mathrm{ZN}$ staining technique in early detection and recovery of $C$. parvum in stool sample as in Figure 1, therefore we recommend to use as first choice in diagnosis of Cryptosporiduim parvum.

\section{Acknowledgement}

The authors would like to thanks all the staffs of Department of Medical Laboratory in Kosti Teaching Hospital and all staffs of Medical Parasitology and Entomology Department in University of El Imam El Mahdi, Kosti, Sudan.

\section{Declaration and conflict of interest}

All authors declare no potential conflict with respect to the research, authorship, and publication of the article.

\section{Appendix}

Questionnaire for studying the role of two permanent staining techniques in diagnosis of Cryptosporidiosis in diarrheic patient's attending to Kosti Teaching Hospital in Kosti locality-White Nile state, Sudan

\section{Questionnaire No. ( ) \\ - Personal information's:- \\ i. Name \\ ii. \\ iii. Age \\ iv}

v. Sex: Male ( ) Female ( )

\section{Clinical information's:-}

i. Do you have latrine in your home? Yes ( ) No ( )

ii. Source of drinking water:

a- Pipe ( ) b- Canal ( ) c- Donkey cart ( )

iii. Do you have these signs or symptoms?

iv. Fever ( ) Headache ( ) diarrheal ( ) vomiting ( ) abdominal pain ()

2. Others

3.

v. Do you have blood or Mucus in Stool? Yes ( ) No ( )

vi. Do you investigate diarrheic stool? Yes () No ()

vii. Do you take anti-parasitic drug? Yes ( ) No ( )

4.Laboratory results:- Stool sample:

5.*Permanents staining technique:-

i. Modified ZN staining technique: positive ( ) negative ( )

ii. Trichrome staining technique: positive ( ) negative ( ) 


\section{References}

1. Current WL, Garcia LS. Cryptosporidiosis. Clin Microbial Rev. $1991 ; 4(3): 225-258$.

2. Chappell CL, Okhuysen PC, White AC. Cryptosporidium parvum infectivity, pathogenesis and the host-parasite relationship. In: Thompson RCA, Armson A,Ryan UM, editors, Cryptosporidium: from molecules to disease. Amsterdam, the Netherlands: Elsevier; 2004:19-49.

3. Casemore DP. Epidemiological aspects of human cryptosporidiosis. Epidemiol Infect. 1990;104:1-28.

4. Lacroix C, Berthier M, Agius G, et al. Cryptosporidium oocysts in immunocompetent children: epidemiological investigations in the day care centres of Poitiers, France. Eur J Epidemiol. 1987;3:381-385.

5. Frost FJ, Muller T, Craun GF, et al. Paired city Cryptosporidium serosurvey in the southwest USA. Epidemiol Infect. 2001;126:301-307.

6. Park JH, Kim HJ, Guk SM, et al. Survey of cryptosporidiosis among 2.541 residents of 25 coastal island in Jeollanam-Do (Province), Republic of Korea. Korean J Parasitol. 2006;44:367-372.

7. Egorov A, Frost F, Muller T, et al. Serological evidence of Cryptosporidium inections in a Russian city and evaluation of risk factors for infections. Ann Epidemiol. 2004;14:129-136.

8. Tzipori S, Baker JR, Muller R, et al. Advances in Parasitology: Opportunistic Protozoa in Humans, Academic Press, London. 1998. p. 40.

9. Zu SX, Fang GD, Fayer R, et al. Cryptosporidiosis - Pathogenesis and Immunology. Parasitol Today. 1992;8(1):24-27.

10. Levine ND, Phylum II Apicomplexa. In: Lee RR, Hutner SH, Bovee EC editors. An Illustrated Guide to the Protozoa, Allen Press, Lawrence: 1985:322-374.

11. Roberts WG, Green PH, Ma J, et al. Prevalence of cryptosporidiosis in patients undergoing endoscopy: evidence for an asymptomatic carrier state. Am J Med.1989;87(5):537-539.

12. Frost FJ, Kunde TR, Muller TB, et al. Serological responses to Cryptosporidium antigens among users of surface vs. ground-water sources. Epidemiol Infect. 2003;131(3):1131-1138.

13. De Santana BB, da Silva TLB, Ramos RAN, et al. Evaluation of Different Parasitological Techniques for Diagnosing Intestinal Parasites in Dogs. Open Journal of Veterinary Medicine, 2015;5:19-24.

14. Abdelrhman AA, Elbashir H, Samira A, et al. Impact of Mass treatment, Snail Control and Health Education on the Prevalence of Schistosoma haematobium among pupils in Rural Areas at Kosti locality - White Nile State - Sudan (2011-2014). .Advance Research Journal of Multidisciplinary Discoveries. 2017;20.0(1):16-22.

15. Tamomh AG, Yousif SR, Weldigorigis TZ, et al. Prevalence of cryptosporidiosis among diarrhoeic patient's attending to kosti teaching hospital, White Nile State, Sudan, wjpmr. 2018;4(2):25-30.

16. Okhuysen PC, Chappell CL, Marshall MM, et al. Infectivity of a Cryptosporidium parvum isolate of cervine origin for healthy adults anti gamma interferon knockout mice. J Infect Dis. 2002;185(9): 1320-1325.

17. Cheesbrough M. District laboratory practice in tropical countries. Part 1. $3^{\text {rd }}$ ed, Cambridge university press. 1999.

18. Sorvillo FJ, Lieb LE, Kerndt PR, et al. Epidemiology of cryptosporidiosis among persons with acquired immunodeficiency syndrome in Los Angeles County. Am J Trop Med Hyg. 1994;51(3):326-331.

19. MacKenzie WR, Hoxie NJ, Proctor ME, et al. A massive outbreak in Milwaukee of Cryptosporidium infection transmitted through the public water supply. N Engl J Med.1994;331(3):161-167.

20. Frost FJ, Muller T, Craun GF, et al. Serological evidence of endemic waterborne Cryptosporidium infections. Ann Epidemiol. 2002;12:222227. 